\title{
DETERMINANTS OF INPATIENT COST FOR PATIENTS WITH ST-ELEVATION MYOCARDIAL INFARCT AT MAYAPADA HOSPITAL, TANGERANG
}

\author{
Willia Gontina S, Atik Nurwahyuni \\ Masters Program in Health Policy and Administration, Faculty of Public Health, Universitas \\ Indonesia, Depok, West Java
}

\begin{abstract}
Background: Inpatient health services for heart attack patients is a complex problem and the highest billing rate in hospitals. Due to the high cost of hospitalization, delay treatment cases may cause fatal health consequences. This study aimed to determine factors affecting the inpatient cost for patients with ST-elevation myocardial infarction at Mayapada hospital, Tangerang, West Java.

Subjects and Method: A cross-sectional study was conducted at Mayapada hospital, Tangerang, West Java, from July to December 2019. A sample of 31 patients diagnosed with ST-elevation myocardial infarction (STEMI) was selected by total sampling. The dependent variable was total inpatient service costs counted according to the clinical pathway. The independent variables were doctor in charge presented the direct cost, age, gender, patient's distance to hospital, payment method, and length of stay. The data were collected using medical records. The data were analyzed by multiple linear regression.

Results: Inpatient service cost in STEMI patients was positively associated with the doctor direct cost $(b=0.51 ; p=0.003)$, distance to hospital $(b=0.13 ; p=0.501)$, and length of stay $(b=$ $0.39 ; \mathrm{p}=0.330$ ). Inpatient service cost in STEMI patients was negatively associated with age $(b=-0.30 ; p=0.107)$, gender $(b=-0.13 ; p=0.550)$, and payment method $(b=-0.26 ; p=0.214)$. Conclusion: Inpatient service cost in STEMI patients have a positive association with the doctor direct cost, distance to hospital, length of stay, and negative association with age, gender, and payment method.
\end{abstract}

Keywords: inpatient service cost, length of stay, STEMI patients

\section{Correspondence:}

Willia Gontina S. Masters Program in Health Policy and Administration, Faculty of Public Health, Universitas Indonesia, Depok, West Java. Email: amyamandacp@gmail.com. Mobile: +6281280778000 . 